\title{
La importancia de la creatividad en el ámbito empresarial
} The Importance of Creativity in the Business World

\author{
Alma Delia Zúñiga-Mera ${ }^{a}$
}

\begin{abstract}
This review exposes the impact of creative practices within organizations. Given that we are in the time of 4.0 Industry it is vital to adopt structural and organizational changes that allow the constant evolution in the way of operating and directing companies.

The text is presented in three essential parts that invite the reader to ask about the current model for solving problems, and how creativity could benefit all the links of an organization. In addition to mentioning the educational aspect, where the bases for innovation and generation of ideas could arise to facilitate the change of flagrant rigidity in most companies.
\end{abstract}

\section{Keywords:}

Creativity, Organization, Innovation, Evolution

\section{Resumen}

La presente reseña expone la repercusión de las prácticas creativas dentro de las organizaciones. Dado que nos encontramos en la época de la industria 4.0 es vital adoptar cambios estructurales y organizacionales que permitan la evolución constante en la manera de operar y dirigir las empresas.

El texto es presentado en tres partes esenciales que invitan al lector a preguntarse sobre el modelo actual para la resolución de problemas, y cómo la creatividad podría beneficiar a todos los eslabones de una organización. Además de mencionar el aspecto educativo, donde podrían surgir las bases para la innovación y generación de ideas que faciliten mudar la rigidez flagrante en la mayoría de las empresas.

\section{Palabras Clave:}

Creatividad, Organización, Innovación, Evolución

\section{Reseña}

En los últimos años se ha percibido el futuro hecho realidad, y con esto la actividad empresarial se ha vuelto dinámica al punto que innovar, ya no es una opción, es innovar o morir (Iturbide, 2018), es por ello que la creatividad se torna importante para la vida de las empresas. El artículo de Marco V. López Paredes que se reseña a continuación toma este punto de partida invitando al lector, en primera instancia, a preguntarse sobre los beneficios de incorporar la creatividad en un ambiente (hasta ahora) frio y hostil, como lo son las organizaciones. En segundo lugar, da apertura a la búsqueda de un cambio organizacional basado en el arte creativo, y como tercer asunto, puntualiza el papel de los gerentes ante la evolución del método tradicional de

a Autor de Correspondencia, Universidad Autónoma del Estado de Hidalgo, Escuela Superior de Tlahuelilpan. Email: alma_zuniga3802@uaeh.edu.mx 
trabajo a uno con mayor flexibilidad y apertura a todos los eslabones.

López Paredes parte de las relaciones entre arte, creatividad y organización, dado que, en épocas anteriores la creatividad había sido asunto alejado del ámbito empresarial porque se asocia al arte. Sin embargo, el arte puede ser definido como la actividad humana específica, para la que se recurre a ciertas facultades sensoriales, estéticas e intelectuales (Larousse , 2000). Lo cual es sabido que es necesario para resolver problemas en un mundo complejo, dinámico y donde las necesidades emergen día a día. Entonces se reafirma que el arte en un contexto organizacional mejora el proceso creativo, necesario para innovar en todas las áreas corporativas que a la vez enriquece la percepción y satisfacción del cliente.

En la primera sección López Paredes menciona que la creatividad es base para la innovación, pero es necesario recalcar que son elementos complementarios para conseguir una posición competitiva ante el dinamismo de la industria, ya que la creatividad consiste en crear algo novedoso y la innovación es incorporar esas ideas a productos y/o servicios que aporten valor al cliente $y$ al mercado (Martínez, 2018). Por consiguiente, al aceptar dicha idea, las organizaciones tienen que abrirse al entorno y revitalizar el contexto al aprovechar el talento humano, que según la metodología de manufactura esbelta es un desperdicio el no usufructuar la creatividad $y$ conocimiento de cada persona, ya sea un empleado, proveedor o cliente. $\mathrm{Y}$ retoma un comentario, donde a mi parecer da en el punto de la relación tratada, al comparar al empresario con el artista, pues ambos "tienen la necesidad de interpretar creativamente la realidad" (López Paredes, 2015).

Para que una organización sea capaz de recoger, compartir y utilizar el conocimiento de cada persona, Marco Vinicio propone que la fuerza de trabajo sea heterogénea, pues es más probable encontrar soluciones creativas a los problemas cuando los ataca un grupo diverso. $Y$ dado que nos encontramos en la era donde las empresas luchan por ser únicas y las más creativas, se deben explotar los recursos para sobresalir, pues la originalidad no es suficiente. Para que la innovación sea exitosa, una idea debe ser apropiada, útil y viable. Entonces, ¿cómo se logra cambiar a todo un monstruo organizacional a un ambiente artístico?
Mejorando el entorno, para fomentar la creatividad y apertura a la opinión, como CultHunting lo ha hecho al combinar la potencia creativa de los artistas, con la necesidad de innovación y pasión de los empresarios (Fernández, 2015).

Existen empresas con un modus operandi antiguo pero que aún rinde frutos, sin embrago corren el riesgo de desaparecer por la competencia. Es ahí dónde López Paredes, en la segunda parte de su artículo se enfoca en el puesto de dirección para cuestionar las prácticas que afectan a la creatividad. En su mayoría son efecto de la rigidez con la que se labora, pues no hay permisiones. Para erradicar dicha práctica se propone fomentar el diálogo, trabajo en equipo, muestras de artes visuales o sonoras, escucha activa por parte de los altos rangos y la puesta en marcha de las buenas ideas. Lo que a su vez da flexibilidad a la empresa, ventaja que se torna indispensable para reaccionar al cambio de forma efectiva y reducir el riesgo de catástrofes (Martínez, 2018).

Como consecuencia al mejorar el entorno laboral, todos los empleados se vuelven autotélicos, es decir que se sienten gratificados con las actividades que realizan (Larousse, 2000) y se vuelven independientes, auténticos y decididos a tener participación activa en las tareas que desempeñan. A fin de lograr dicho contexto es necesario el estímulo por parte de la dirección de modo que potencie el afloramiento del talento creativo, para así obtener el beneficio mencionado por el autor del artículo, de ofrecer servicios y productos de calidad, dando una buena imagen al cliente de tener un alto interés por la cultura y bienestar de los involucrados. El estímulo (no monetario) antes mencionado, debe surgir de los gerentes, puesto que son ellos quienes tienen un puesto de mando y a su vez la responsabilidad de guiar con el ejemplo. Ya que como menciona Marco en la tercera parte del escrito, la creatividad del ejecutivo es la que permite un mejor análisis para la toma de decisiones, búsqueda de alternativas y solución de problemas. Lo que es de suma importancia en una época donde el conocimiento es poder, puesto que siempre habrá algo que innovar, ya sea un producto, un sistema, alguna estructura o un método de dirección. Es ahí donde el gerente se vuelve un ser activo y reactivo para incentivar la habilidad de crear y aplicar ideas, que a su vez se vuelve la vitalidad de la empresa para adaptarse a las circunstancias actuales. 
Actualmente el cliente es quien demanda calidad, precio y servicio, de ahí que las empresas busquen opciones para competir en el mercado $y$ posicionarse fuertemente. Ya se ha hablado sobre el papel del gerente, que se necesita que sean líderes creativos, pero, ¿cuál es la responsabilidad de todos los demás actores dentro de la organización? Generar ideas y comunicarse de forma vertical y horizontal en todos los eslabones que agregan valor a la empresa y no sólo al producto final. Además, que esas prácticas enriquecen la efectividad interna, pues al modernizar los procedimientos se reducen tiempos, mejora la productividad y se logran ahorros en gastos innecesarios (Martínez, 2018). Es por eso que la creatividad es una opción para que el mañana sea mejor que hoy.

Es importante mencionar que Marco sugiere desarrollar el pensamiento creativo en las actividades de conducción, capacitación y organización para obtener mejor capacidad de resolución de problemas. Sin embargo, considero que la empresa no debería tener todo el trabajo de motivar la creatividad si desde el ámbito escolar se tomara como parte de la cultura, la generación de ideas, pues cuando las mentes están frescas la innovación educativa es un proceso abierto que implica la reflexión desde la práctica (Terapuez \& Lima, 2013), ya que brinda al estudiante herramientas vitales para acrecentar su forma de pensar y asumir el mundo, lo que posiblemente le facilitará el acceso al mundo laboral.

En conclusión, el arte y la gestión empresarial se encuentran altamente ligadas, el problema es que aún no se ha enfocado en su totalidad como recurso de solución y mejora continua. El artículo de López Paredes es útil y te invita a cuestionarte sobre la actualidad, además al ser de fácil entendimiento, te da a conocer hechos interesantes sobre la creatividad empresarial. En mi opinión la creatividad debería permitirse desde los docentes hacia los alumnos para mejorar el modelo educativo que se está volviendo anticuado, para permitir que haya más ciudadanos que generen ideas de valor. A la vez algunas empresas al ver la necesidad actual de evolucionar a la par de la tecnología han creado programas para invitar a los jóvenes estudiantes a participar en el desarrollo de propuestas y cambios innovadores en el entorno real (como es el caso de Volkswagen México, Grupo Modelo, entre otras), pues creen en el talento de las nuevas generaciones. Permitamos imaginar, que es donde surge el proceso creativo, para dar paso a la innovación, la cual demanda una aceptación y apropiación del cambio por parte de aquellos que han de llevarla a cabo (Terapuez \& Lima, 2013). itativa.

\section{Referencias}

\section{Reseña de Artículo:}

El Arte como herramienta para liberar la creatividad en las Organizaciones

Razón y Palabra, Vol. 19 núm. 89

Instituto Tecnológico y de Estudios Superiores de Monterrey. Estado de México

Autor: Mauricio Vinicio López Paredes

Año: 2015

[1] López Paredes, Marco Vinicio (2015). El arte como herramienta para liberar la creatividad en las organizaciones. Razón y Palabra, vol. 19, núm. 89. Instituto Tecnológico y de Estudios Superiores de Monterrey, Estado de México. 